\title{
Ortogranulitos de Mangaratiba, Rio de Janeiro, uma janela para o Arqueano no Orógeno Ribeira: litogeoquímica e geoquímica isotópica de $\mathrm{Nd}$ e $\mathrm{Sr}$
}

\author{
Orthogranulites from Mangaratiba, Rio de Janeiro, Brazil, a window for the \\ Archean in the Ribeira belt: lithogeochemistry and isotopic geochemistry of Nd and Sr
}

\author{
Jefferson Lima Fernandes André ${ }^{1}$ (D), Claudia Sayão Valladares ${ }^{2}$ (D), Beatriz Paschoal Duarte ${ }^{2}$ (D) \\ ${ }^{1}$ Universidade Federal do Espírito Santo - UFES, Centro Universitário Norte do Espírito Santo, Departamento de Ciências \\ Naturais, Rodovia BR 101 Norte, Km 60, Litorâneo, CEP 29932-900, São Mateus, ES, BR (jeffersonlfandre@hotmail.com) \\ ${ }^{2}$ Universidade do Estado do Rio de Janeiro - UFRJ, Faculdade de Geologia, Departamento de Geologia Regional e \\ Geotectônica, Rio de Janeiro, RJ, BR (claudia.s.valladares@gmail.com; biapasch@gmail.com)
}

Recebido em 27 de novembro de 2019; aceito em 23 de dezembro de 2020

\begin{abstract}
Resumo
O presente estudo visou contribuir com o entendimento da gênese dos ortogranulitos arqueanos (ca. 2,65 Ga) que afloram na região de Mangaratiba, Rio de Janeiro, e que foram denominados em um estudo recente de Ortogranulitos Ribeirão das Lajes. Os granulitos são homogêneos, constituídos principalmente de quartzo, K-feldspato e plagioclásio (esverdeado), com biotita, clinopiroxênio e ortopiroxênio como os máficos mais comuns. Composicionalmente, os protólitos são granitos e granodioritos. A análise de litogeoquímica revelou que os granulitos são metaluminosos, representando séries de alto e médio-K, correlacionáveis a granitos de arco. O comportamento de elementos terras raras (ETR) ainda revela que provavelmente devem existir diferentes suítes cogenéticas nos ortogranulitos. Porém, em razão do quantitativo de análises, não foi possível definir com maior acurácia todas as possíveis suítes. Foram ainda realizadas análises de $\mathrm{Sm} / \mathrm{Nd}$ e $\mathrm{Rb} / \mathrm{Sr}$ no mesmo ortogranulito datado em trabalho recente como arqueano (MAN-JEF-01a), e foi obtida uma idade modelo $\mathrm{T}_{\mathrm{DM}}$ de aproximadamente $2,7 \mathrm{Ga}$. Seu $\varepsilon_{\mathrm{Nd}(t)}$ positivo $(+2,1)$ aponta para origem a partir do manto depletado, apesar da $\operatorname{razão}{ }^{87} \mathrm{Sr}^{86} \mathrm{Sr}_{(\mathrm{t})}$ calculada $(0,70529)$ indicar alguma contribuição crustal (fonte enriquecida). Os dados obtidos neste estudo sugerem que os ortogranulitos de Mangaratiba foram formados em ambiente de arco magmático no Neoarqueano, a partir de uma fonte mantélica envolvendo assimilação crustal.
\end{abstract}

Palavras-chave: Ortogranulitos; Mangaratiba (RJ); Litogeoquímica; Geoquímica isotópica; Ribeirão das Lajes.

\begin{abstract}
The present study has a goal to contribute to the understanding of the origin of the Archean granulites (ca. $2.65 \mathrm{Ga}$ ) of the region of Mangaratiba (RJ), that was recently denominated Orthogranulites Ribeirão das Lajes. The granulites are homogeneous, consisting mainly of quartz, K-feldspar and plagioclase (greenish), with biotite, clinopyroxene and orthopyroxene as the most common mafic minerals. The protoliths are granites and granodiorites compositions. The lithogeochemistry data indicate they are medium to high-K calc-alkaline with metaluminous compositions, corresponding to granites from the arc. The analysis of Rare Earth Elements (REE) reveals there are different cogenetic suits of rock between granulites. However, due to the number of analyses, it was not possible to more accurately define all possible suites. $\mathrm{Sm} / \mathrm{Nd}$ and $\mathrm{Rb} / \mathrm{Sr}$ analyses were also performed on the same orthogranulite dated in a recent work as an Archean (MAN-JEF-01a), and a $T_{D M}$ model age obtained has approximately $2.7 \mathrm{Ga}$ was obtained. Its positive $\varepsilon_{\mathrm{Nd}(\mathrm{t})}(+2.1)$ indicates a rock from the depleted mantle, despite the calculated ${ }^{87} \mathrm{Sr} /{ }^{86} \mathrm{Sr}_{(\mathrm{t})}$ ratio (0.70529), indicates some crustal contribution (enriched source). The data obtained here suggest that the orthogranulites of Mangaratiba $(\mathrm{RJ})$ may be products of magmatism in the Neoarchean, from a mantle source involving crustal assimilation.
\end{abstract}

Keywords: Orthogranulites; Mangaratiba (RJ); Lithogeochemistry; Isotopic geochemistry; Ribeirão das Lajes. 


\section{INTRODUÇÃO}

Em Mangaratiba, região da Costa Verde do estado do Rio de Janeiro, afloram ortogranulitos arqueanos (ca. 2,65 Ga), recentemente denominados de Ribeirão das Lajes (André et al., 2018). Por apresentarem paragênese de fácies granulito e ocorrerem próximos a rochas metassedimentares do Terreno Ocidental - segundo o mapa regional do Orógeno Ribeira - (Heilbron et al., 2010) (Figura 1), esses granulitos já foram considerados como uma lasca tectônica do Complexo Juiz de Fora (CJF) (Dios, 1995; Heilbron et al., 2007b). Existe uma clara diferença litológica entre eles, uma vez que o CJF possui ampla variedade composicional — de charnockitos a enderbitos, e noritos -, enquanto os granulitos de Mangaratiba são compostos essencialmente de granitos e granodioritos. Em um estudo recente (André et al., 2018), ficou claro que os ortogranulitos de Mangaratiba são mais antigos (Arqueanos) que os do CJF, que são do Paleoproterozoico (Heilbron et al., 2004; Noce et al., 2007; Fernandes André et al., 2009; Heilbron et al., 2010).

André et al. (2018) consideram que os ortogranulitos arqueanos de Mangaratiba representam o embasamento da área, visto que cristais de zircão de herança arqueana foram encontrados nas rochas gnáissicas paleoproterozoicas que

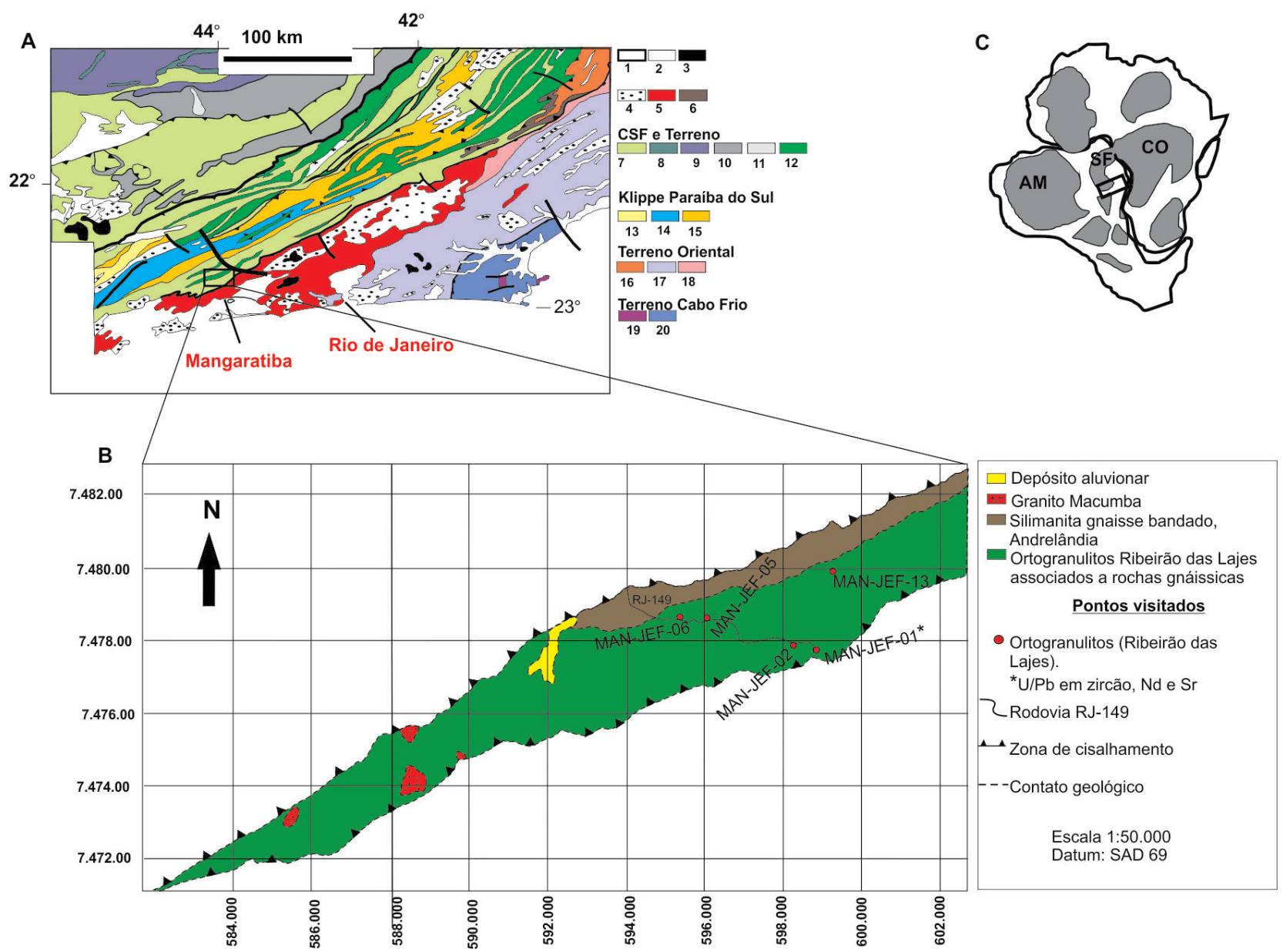

1: Localização da área de estudo no mapa da Orógeno Ribeira; 2: sedimentos quaternários, sedimentos terciários; 3: rochas alcalinas; 4 a 6: rochas magmáticas neoproterozoicas (4: granitoides brasilianos sin a pós-colisionais; 5: Arco Magmático Rio Negro; 6: Arco Magmático Serra da Bolívia); 7 a 12: Unidade do Cráton do São Francisco e do Terreno Ocidental (7: rochas metassedimentares meso a neoproterozoicas (590 - $560 \mathrm{Ma}) ;$ : : rochas metassedimentares paleo e mesoproterozoicas, embasamento associado; 9: Complexo Barbacena; 10: Complexo Mantiqueira; 11: Complexo Alcalino Matola; 12: Complexo Juiz de Fora); 13 a 15: Unidade da Klippe Paraíba do Sul (13: Complexo Embú; 14: Complexo Paraíba do Sul; 15: Complexo Quirino); 16 a 18: unidades do Terreno Oriental: rochas metassedimentares dos grupos Cambuci, Costeiro e Italva; 19 e 20: unidades do Terreno Cabo Frio (19: rochas metassedimentares do Grupo Búzios; 20: complexo do embasamento Região do Lagos).

Figura 1. (A) Mapa geológico simplificado do Orógeno Ribeira (fonte: modificado de Heilbron et al., 2010); (B) mapa base utilizado neste estudo. Essa faixa de rochas (em verde) fora associada ao Complexo Juiz de Fora e denominada de Unidade Granulítica Ponte de Zinco (fonte: modificado de Dios, 1995); (C) cenário do paleocontinente Gondwana Ocidental. As áreas em cinza são os Crátons Amazônico (AM), São Francisco (SF) e Congo (CO). 
ocorrem na região. Os autores denominaram esse embasamento de Ortogranulitos Ribeirão das Lajes. Essa mesma denominação também será utilizada neste artigo.

Como esse conjunto de rochas granulíticas (Ribeirão das Lajes) foi definido recentemente, suas unidades não foram ainda mapeadas, razão pela qual o mapa base utilizado durante a pesquisa e apresentado aqui, que deverá ser revisto, foi confeccionado por Dios (1995) (Figura 1) e pode ser encontrado na folha Volta Redonda (1:100.000) (Heilbron et al., 2007b). A autora supracitada denominou uma faixa de rocha onde afloram os granulitos de Unidade Granulítica Ponte de Zinco, com a intenção de correlacionar essa unidade ao CJF (como mencionado anteriormente). Dessa forma, os ortogranulitos são encontrados nessa faixa junto com outras rochas gnáissicas (ortoderivadas e paraderivadas).

$O$ presente artigo teve o objetivo de estudar as fontes desses ortogranulitos arqueanos (Ribeirão das Lajes), visando contribuir com o entendimento do seu significado tectônico. Para isso, foram realizadas análises petrográfica, litogeoquímica e de isótopos de $\mathrm{Nd}$ e $\mathrm{Sr}$. Os resultados são apresentados e discutidos adiante.

\section{CONTEXTO GEOLÓGICO}

A área estudada está inserida no contexto geológico do Orógeno Ribeira e está localizada na porção sul dele. Pelo mapa geológico da folha Volta Redonda (1:100.000) (Heilbron et al., 2007b), a faixa denominada por Dios (1995) de Unidade Granulítica Ponte de Zinco está em contato com rochas metassedimentares do Domínio Tectônico Andrelândia. Esse domínio, junto ao Domínio Juiz de Fora e ao Autóctone, forma o Terreno Ocidental, o qual representa a margem passiva retrabalhada do Cráton São Francisco envolvida na Orogenia Brasiliana-Pan-Africana (Heilbron et al., 2004).

O CJF representa o embasamento do Domínio Tectônico Juiz de Fora (Heilbron et al., 2004) e é representado na área por parte das rochas estudadas neste artigo (Dios, 1995; Heilbron et al., 2007b). No atual estado do conhecimento, o CJF é caracterizado como um conjunto de ortogranulitos que possui ampla variedade litológica, desde charnockitos a enderbitos calcioalcalinos de 2,1 Ga, noritos toleíticos de $2,4 \mathrm{Ga}$, incluindo ainda rochas básicas alcalinas de 1,7 Ga (Duarte, 1998; Heilbron et al., 2004; Fernandes André et al., 2009; Heilbron et al., 2010). Muitos autores sugerem que o CJF teria sido formado durante o evento Transamazônico, e que esse mesmo evento teria originado a paragênese de fácies granulito (Delhal et al., 1969; Cordani et al., 1973; Heilbron, 1993; Machado et al., 1996; Nogueira et al., 2004), tendo a orogenia Brasiliana retrometamorfizado sua paragênese (Duarte, 1998; Duarte et al., 2000; Nogueira et al., 2004). O CJF também compõe parte do embasamento do Orógeno Araçuaí, no estado do Espírito Santo (Noce et al., 2007).
Anteriormente ao trabalho de Dios (1995), na folha Mangaratiba (1:50.000), podemos destacar Sperling et al. (1983), que revelam a ocorrência de rochas charnockíticas e granulíticas no NE da folha, associadas a um conjunto de rochas gnáissicas, definidas, na época, de Unidade Itaocara (aflorando mais especificamente na Unidade Itaocara II). Sperling et al. (1983) ainda correlacionam essas ocorrências à Suíte Charnockítica da Unidade Ilha Grande, onde também incluem o charnockito do Morro do Papagaio, que fica na divisa com o estado de São Paulo (Folha Pincinguaba, 1:50.000). Entretanto, segundo Fernandes (2001 apud Heilbron et al., 2007a, 2016), a Suíte Charnockítica da Ilha Grande possui idade $\sim 541,4 \pm$ 9,3 Ma (TIMS U/Pb).

A Unidade Granulítica Ponte de Zinco, definida assim por Dios (1995) (Figura 1B), ocorre entre Rio Claro (RJ) e Mangaratiba (RJ). Segundo a autora, trata-se de uma faixa de rochas granulíticas alongada na direção NE-SW e inserida entre rochas metassedimentares dessa região por zonas de cisalhamento (Figura 1). A intenção de agrupar essas rochas está na possibilidade de representar um conjunto correlacionável ao CJF. Porém, como é destacado em Dios (1995), o litotipo predominante dessa unidade é um granitoide, quartzo-feldspático, que possui coloração clara. O ortopiroxênio, que nesse tipo de rocha indicaria condições de fácies granulito, não aparece na análise modal desse granitoide. Para a autora, o granitoide seria o neossoma resultante do processo de anatexia a que o conjunto granulítico foi submetido. Os granulitos da região, propriamente ditos, seriam restitos dessa anatexia, ocorrendo como enclaves nesse granitoide, formando uma associação migmatito-granulito. Duas rochas gnáissicas da região, de aproximadamente $2,1 \mathrm{Ga}(\mathrm{U} / \mathrm{Pb}$ em zircão), analisadas por André et al. (2018), talvez representem esse granitoide citado por Dios (1995). No entanto, os dados de $\varepsilon_{\mathrm{Nd}(t)}(+3,3$ e $+2,3)$ indicam que essas rochas não foram formadas por fusão crustal (Fernandes André, 2014).

Heilbron et al. (2007b) também consideram que na região ocorrem rochas granulíticas relacionadas ao CJF, pois é comum no estado do Rio de Janeiro e em Minas Gerais a ocorrência de escamas tectônicas do referido complexo interdigitadas a rochas metassedimentares por zonas de cisalhamento.

No entanto, André et al. (2018) obtiveram idade arqueana $\sim 2,6 \mathrm{Ga}$ (U-Pb em zircão, por LA-ICPMS) para um granulito dessa unidade que, em conjunto com os dados de campo e petrográficos, mostra que as rochas estudadas não representam uma lasca tectônica do CJF. Os autores denominaram esse conjunto de ortogranulitos da região, de Ribeirão das Lajes, pois eles representam o embasamento da unidade estudada, uma vez que foram encontradas heranças de idades arqueanas nas rochas gnáissicas da região. Como mencionado anteriormente, além dos granulitos, dentro da Unidade Granulítica (Dios, 1995) foram encontrados, por André et al. (2018), paragnaisse contendo granada, silimanita e cordierita, gnaisse leucocrático e um gnaisse com granada 
(os dois últimos também foram analisados pelo método U/ $\mathrm{Pb}$ ). Os autores apresentam, ainda, idades de metamorfismo de 647 e 631 Ma para as rochas gnáissicas, que são mais antigas do que as da fase pré-colisional do Orógeno Ribeira, sugerida como $630 \mathrm{Ma}$ (Heilbron e Machado, 2003). Isso aponta para um evento mais antigo do que o comumente registrado no Terreno Ocidental, e que associado com as heranças arqueanas, sugere que esse conjunto não represente parte desse terreno, e sim outra unidade tectônica.

\section{MÉTODOS ANALÍTICOS}

A preparação das amostras, para análises litogeoquímica e isotópica, foi realizada no Laboratório Geológico de Processamento de Amostras (LGPA) da Faculdade de Geologia da Universidade do Estado do Rio de Janeiro (FGEL/UERJ).

As amostras preparadas foram enviadas ao Activation Laboratories LTD (ACTLABS), em Ontário, Canadá, onde foram realizadas as análises de rocha total para elementos maiores por meio do método Inductively Coupled Plasma Atomic Emmission Spectrometry (ICP-AES), com limite de detecção de $0,01 \%$ peso. Elementos-traço e ETR foram analisados por Inductively Coupled Plasma - Mass Spectrometry (ICP-MS). Os ETR analisados e seus respectivos limites de detecção, em ppm, segundo informações do laboratório, são: $\mathrm{La}, \mathrm{Yb}, \mathrm{Ce}, \mathrm{Tb}, \mathrm{Sm}$ e Nd $(0,01)$, Eu $(0,05)$ e Lu $(0,04)$.

As análises Sm-Nd foram realizadas no Centro de Pesquisas em Geocronologia e Geoquímica Isotópica (CPGeo), da Universidade de São Paulo (USP), por diluição isotópica, segundo metodologia descrita em Sato et al. (1995). O CPGeo utiliza o espectrômetro de massa Finnigan, modelo TRITON, com multicoletores com copos de Faraday. Primeiramente, foi utilizada uma resina de troca iônica para separação dos ETR, seguida pela resina LN para a coleta de Sm-Nd. Os erros para as razões ${ }^{147} \mathrm{Sm} /{ }^{144} \mathrm{Nd} \mathrm{e}{ }^{143} \mathrm{Nd} /{ }^{144} \mathrm{Nd}$ foram calculados para $1 \sigma$ e $2 \sigma$, respectivamente. A média para razão ${ }^{143} \mathrm{Nd} /{ }^{144} \mathrm{Nd}$ foi obtida do padrão JNDI $=0,512098$ \pm 9 e normalizada para ${ }^{146} \mathrm{Nd} /{ }^{144} \mathrm{Nd}$ de DePaolo (1981). $\mathrm{O}$ branco analítico para $\mathrm{Nd}=22 \mathrm{~g}$. A idade modelo $\left(\mathrm{T}_{\mathrm{DM}}\right)$ foi calculada usando o modelo de manto depletado de DePaolo (1981) e seu $\varepsilon_{\mathrm{Nd}}$ calculado para idade de cristalização de 2,65 Ga (André et al., 2018). As concentrações de Rb e Sr foram obtidas por fluorescência de raios X (FRX). Os erros das razões isotópicas ${ }^{87} \mathrm{Sr} /{ }^{86} \mathrm{Sr}$ foram calculados para $2 \sigma \mathrm{e}$ normalizados para ${ }^{87} \mathrm{Sr} /{ }^{88} \mathrm{Sr}=0,1194$, sendo o valor médio da razão ${ }^{87} \mathrm{Sr} r{ }^{86} \mathrm{Sr}$ do padrão NBS-987 $=0,710258 \pm 46$.

\section{GEOLOGIA LOCAL}

A área de estudo está localizada na Costa Verde do estado do Rio de Janeiro e pode ser acessada pela rodovia estadual RJ-149
(Figura 1B), que liga Mangaratiba e Rio Claro. As rochas são encontradas em afloramentos em cortes de estrada, em formas lajes e em meia encosta. Seis amostras dos ortogranulitos foram coletadas (em cinco pontos), das quais poucas apresentam capa de alteração, estando a maior parte aparentemente pouco alterada por intemperismo. A Tabela 1 contém as coordenadas (UTM - SAD 69) dos pontos estudados.

O ortogranulito normalmente é homogêneo (Figura 2A) de coloração esverdeada (Figura 2B), podendo, às vezes, apresentar coloração mais clara (Figura 2C). Possui foliação, mas que não é observada por todo o litotipo, e a granulação varia de muito fina a média, porém ocorrem alguns porfiroblastos/porfiroclastos de plagioclásio e ortopiroxênio que podem ser vistos a olho nu. Raras porções leucossomáticas podem ser encontradas nela (Figura 2D), assim como enclaves máficos, encontrados apenas em um ponto (André et al., 2018).

Pela análise microscópica, foi confirmada a presença de ortopiroxênio em todas as amostras coletadas (seis amostras), atestando que a rocha foi submetida ao metamorfismo de fácies granulito. Porém, um possível evento de retrometamorfismo pode ter ocorrido, pois são encontradas biotita e/ou hornblenda nas bordas do ortopiroxênio e do clinopiroxênio, respectivamente. Os granulitos possuem textura granoblástica (Figuras 3A e 3B), características de deformação dúctil, como fitas (ribbons) de quartzo em algumas amostras (Figura $3 \mathrm{C}$ ), às vezes com matriz poligonizada (Figura 3D). São constituídos principalmente de quartzo, K-feldspato, plagioclásio, biotita (Figuras 3E e 3F), clinopiroxênio e ortopiroxênio, e o total dos máficos pode variar entre 10 e 28\% (André et al., 2018). Exsoluções nos grãos de plagioclásio e em K-feldspato são encontradas em várias amostras, assim como alteração deles para minerais secundários, como sericita/muscovita e carbonato.

O feldspato é encontrado como mineral da matriz e como porfiroblasto/porfiroclasto. São hipidiomórfico a xenomórfico, sendo a geminação uma característica da maioria dos grãos. Em algumas amostras o microclínio coexiste com o ortoclásio. O quartzo aparece na matriz e em forma de ribbons (fitas de quartzo). O piroxênio normalmente acha-se fraturado e é encontrado tanto na matriz quanto em

Tabela 1. Tabela de pontos estudados dos ortogranulitos arqueanos de Mangaratiba, Rio de Janeiro.

\begin{tabular}{lc}
\hline Pontos & Coordenadas UTM \\
\hline MAN-JEF-01 & 0598667E/7477746N \\
MAN-JEF-02 & 0598163E/7477889N \\
MAN-JEF-05 & 0596159E/7478484N \\
MAN-JEF-06 & 0595699E/7478516N \\
MAN-JEF-13 & 0599138E/7479896N \\
\hline
\end{tabular}


porfiroblastos/porfiroclastos. O clinopiroxênio é translúcido, levemente esverdeado e com alta birrefringência, enquanto o ortopiroxênio é translúcido levemente avermelhado e com baixa birrefringência. Já a biotita é encontrada nas bordas dos piroxênios e na matriz, definindo a foliação da rocha, com ou sem pleocroísmo.

Os resultados da análise modal por contagem de 500 pontos, realizada por André et al. (2018), revelaram que os protólitos dessas rochas são composicionalmente granitos (monzogranitos e sienogranitos) e granodioritos (Figura 4).

\section{LITOGEOQUÍMICA}

A caracterização litogeoquímica consistiu na análise de cinco amostras de ortogranulitos. Quatro amostras apresentaram LOI (Loss on Ignition) elevado, mas esses valores provavelmente se devem à formação de minerais secundários, como carbonatos e muscovita/sericita, identificados pela análise microscópica. $\mathrm{O}$ fechamento das análises variou pouco, entre 98,36 e $99,06 \%$ (em peso). Os dados foram inseridos no programa NEWPET, em que foram recalculados para base anidra. A análise revelou que os ortogranulitos correspondem a dois litotipos ácidos e três intermediários. Os resultados estão apresentados nas Tabelas 2A, 2B e 2C.

Os ortogranulitos intermediários e ácidos são classificados como rochas das séries subalcalina e calcioalcalina, segundo os diagramas de classificação de Irvine e Baragar (1971) (Figuras 5A e 5B). Com base no índice de saturação alumina (ISA), elas são classificadas como metaluminosas (Figura 5C). O diagrama de Le Maitre (1989) as classifica como representantes de suítes de médio (MAN-JEF-02 e 05) a alto-K (MAN-JEF-01, 05a e 06) (Figura 5D). No diagrama de classificação de rochas ígneas de Middlemost (1985), os ortogranulitos estudados classificam-se como granitos e granodioritos (Figura 5E).

\section{Ambiente tectônico}

No diagrama de discriminação de ambiente tectônico de Pearce et al. (1984), as amostras estudadas ocupam, principalmente, o campo de granitos de arco vulcânico (Figura 6A).
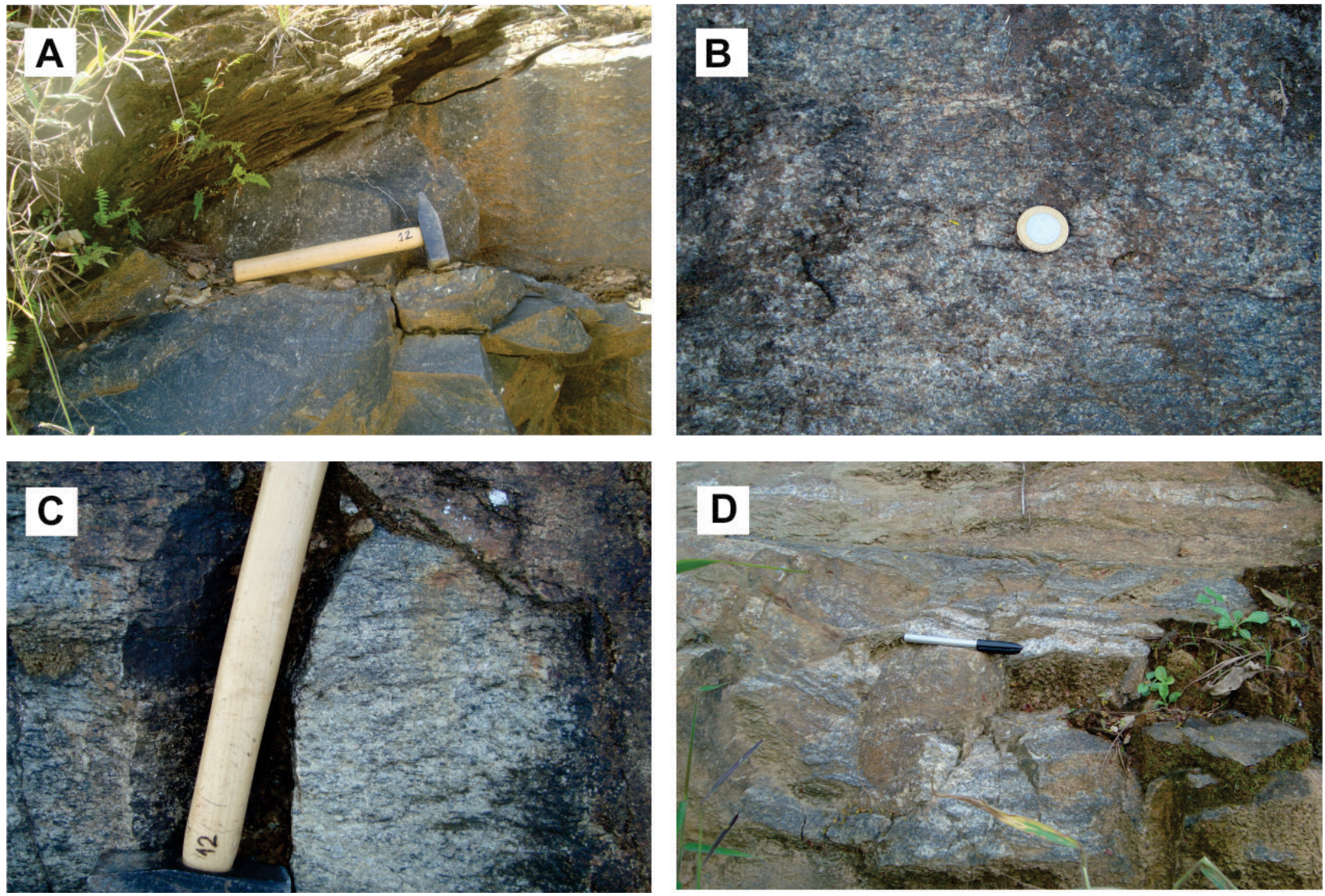

Figura 2. Aspecto dos ortogranulitos observado em campo. (A) Ortogranulito homogêneo no ponto MAN-JEF-01 ( 2,65 $\mathrm{Ga}, \mathrm{U}-\mathrm{Pb}$ em zircão); (B) coloração esverdeada mais comumente observada (ponto MAN-JEF-13); (C) aspecto mais claro do ortogranulito do ponto MAN-JEF-06; (D) porções leucossomáticas orientadas, observadas no ponto MAN-JEF-05. 
Com exceção da amostra MAN-JEF-06, que se assemelha com os granitos de arco do Chile (Figura 6B), as demais se assemelham aos granitos de arco da Jamaica (Figura 6C), sugerindo, assim, assinatura geoquímica e ambiente tectônico semelhantes entre elas. A normalização foi feita para granitos de cristas meso-oceânicas (ORG) de Pearce et al. (1984).
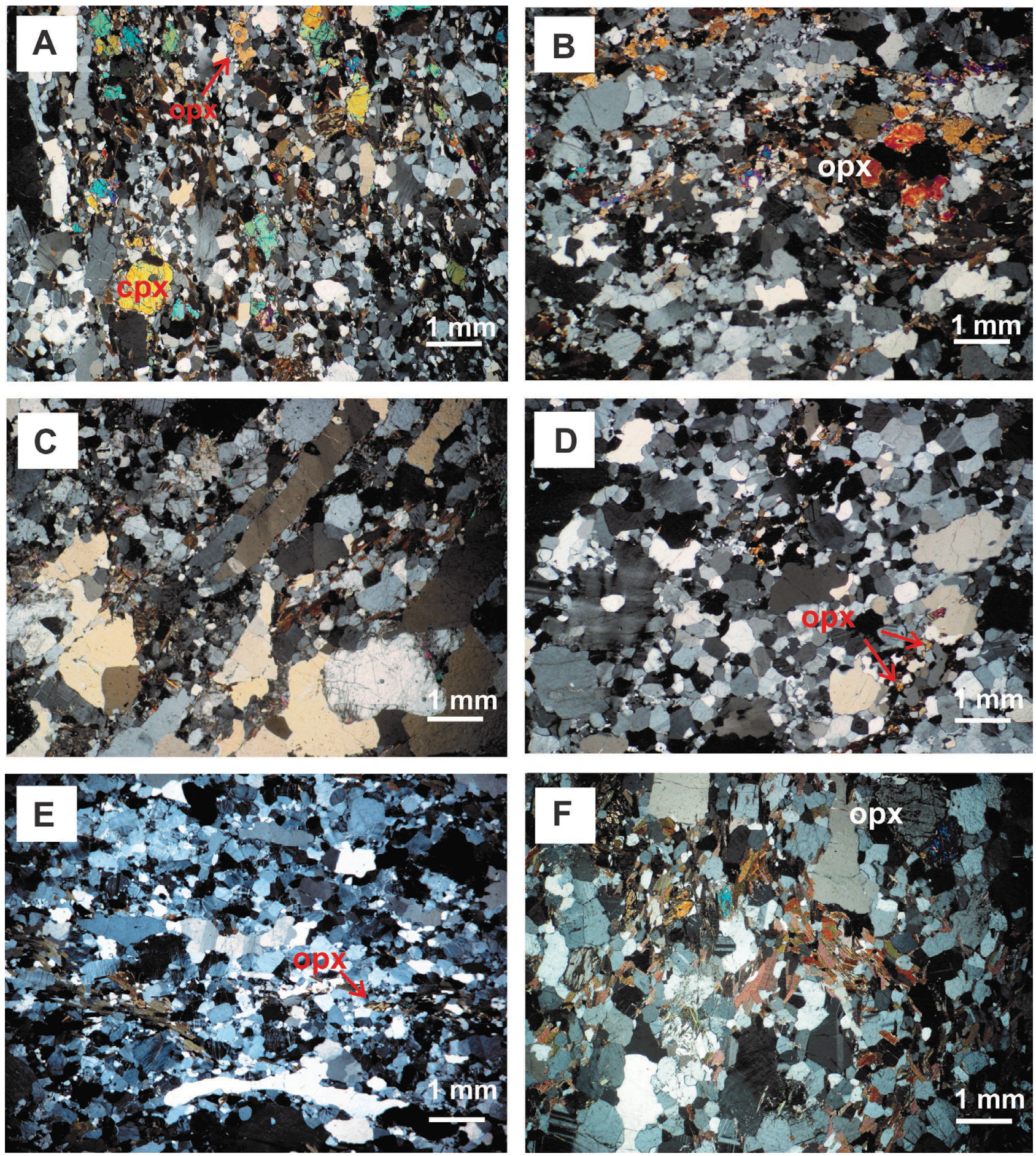

Fonte: André et al. (2018).

Figura 3. Fotomicrografias dos ortogranulitos mostrando as texturas granoblásticas, a presença de ortopiroxênio (opx) e clinopiroxêncio (cpx), ribbons e grãos poligonais: (A) MAN-JEF-01a; (B) MAN-JEF-02; (C) MAN-JEF-05a; (D) MANJEF-06; (E) MAN-JEF-13; (F) MAN-JEF-05c. 


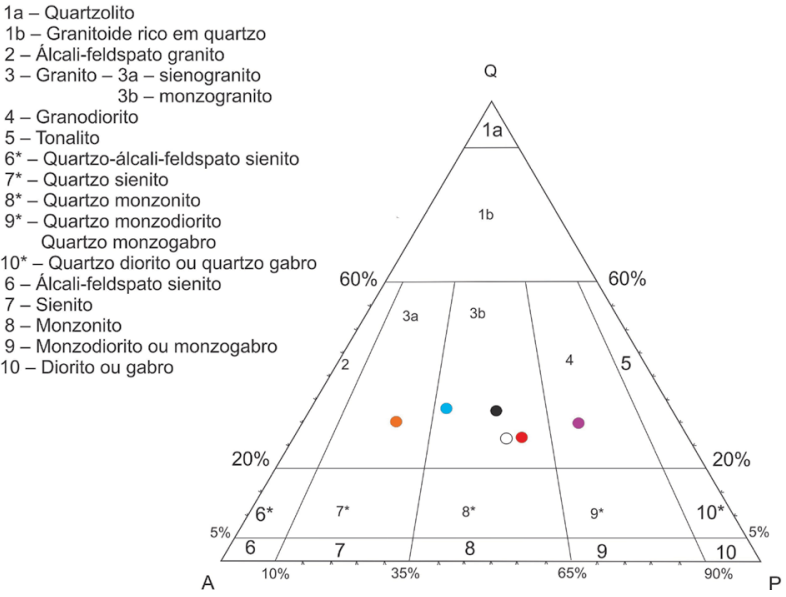

MAN-JEF-01a: círculo vermelho; MAN-JEF-02: círculo preto; MAN-JEF-05a: círculo branco; MAN-JEF-05c: círculo púrpura; MAN-JEF-06: círculo azul; MAN-JEF-13: círculo laranja.

Fonte: André et al. (2018).

Figura 4. Diagrama QAP de Streckeisen (1976) dos ortogranulitos de Mangaratiba.

\section{Geoquímica dos elementos terras raras}

A análise baseada nos ETR fez-se necessária para verificar se existem diferenças petrogenéticas entre as rochas analisadas para as séries calcioalcalinas definidas. Para tal, as concentrações dos ETR foram normalizadas para o condrito de Boynton (1984). A Tabela 3 disponibiliza os valores das razões [ $\mathrm{La} / \mathrm{Yb}$ ] ${ }_{N}$, os valores das anomalias de $\mathrm{Eu} / \mathrm{Eu}^{*}$ e os teores de $\mathrm{SiO}_{2}$. E importante ressaltar que não é a intenção definir os prováveis grupos cogenéticos que possam existir entre os ortogranulitos, pois o estudo não possui um quantitativo de dados suficiente para isso - o que será apresentado é mais uma análise qualitativa.

Pelas razões $[\mathrm{La} / \mathrm{Yb}]_{\mathrm{N}}$, observam-se diferenças no fracionamento dos ETR, que podem ser indicativos de diferentes fontes envolvidas ou de diferentes processos de diferenciação magmática. Na série de alto-K, por exemplo, a amostra MAN-JE-06 (Figura 7A) possui a maior razão $[\mathrm{La} / \mathrm{Yb}]_{\mathrm{N}}(40,25)$ devido ao maior enriquecimento de elementos terras raras leves (ETRL) e ao fracionamento de elementos terras raras pesados (ETRP) na fonte. Possui também forte anomalia negativa de $\mathrm{Eu}^{*}(0,33)$, que indica retenção desse elemento na fonte. Essa maior concentração

Tabela 2A. Composição química dos Ortogranulitos Ribeirão das Lajes. Elementos maiores (em \% peso).

\begin{tabular}{lcccccccccccc}
\hline Amostras & $\mathrm{SiO}_{2}$ & $\mathrm{TiO}_{2}$ & $\mathrm{Al}_{2} \mathrm{O}_{3}$ & $\mathrm{Fe}_{2} \mathrm{O}_{3}{ }^{*}$ & $\mathrm{MnO}$ & $\mathrm{MgO}$ & $\mathrm{CaO}$ & $\mathrm{Na}_{2} \mathrm{O}$ & $\mathrm{K}_{2} \mathrm{O}$ & $\mathrm{P}_{2} \mathrm{O}_{5}$ & LOI & Total \\
\hline MAN-JEF-01a & 66,35 & 0,31 & 13,41 & 4,08 & 0,09 & 1,75 & 2,88 & 3,19 & 3,92 & 0,18 & 2,55 & 98,71 \\
MAN-JEF-02 & 63,49 & 0,6 & 13,53 & 5,84 & 0,10 & 3,68 & 4,49 & 3,36 & 2,68 & 0,15 & 1,14 & 99,06 \\
MAN-JEF-05a & 63,82 & 0,6 & 13,95 & 4,99 & 0,08 & 2,53 & 3,42 & 3,42 & 2,86 & 0,17 & 2,73 & 98,57 \\
MAN-JEF-05C & 61,36 & 0,59 & 14 & 6,25 & 0,11 & 3,18 & 4,79 & 3,65 & 1,79 & 0,3 & 2,34 & 98,36 \\
MAN-JEF-06 & 70,91 & 0,66 & 11,8 & 5,43 & 0,06 & 0,57 & 1,85 & 2,66 & 4,03 & 0,13 & 0,68 & 98,77 \\
\hline
\end{tabular}

LOI: Loss on Ignition.

Tabela 2B. Composição química dos Ortogranulitos Ribeirão das Lajes. Elementos-traços (em ppm).

\begin{tabular}{lccccccccccccccccccccc}
\hline Amostras & $\mathbf{S c}$ & $\mathbf{V}$ & $\mathbf{B a}$ & $\mathrm{Sr}$ & $\mathbf{Y}$ & $\mathbf{Z r}$ & $\mathbf{C r}$ & $\mathrm{Co}$ & $\mathbf{N i}$ & $\mathbf{C u}$ & $\mathbf{Z n}$ & $\mathrm{Ga}$ & $\mathrm{Rb}$ & $\mathbf{N b}$ & $\mathbf{H f}$ & $\mathrm{Ta}$ & $\mathrm{W}$ & $\mathrm{Ti}$ & $\mathrm{Pb}$ & $\mathrm{Th}$ & $\mathbf{U}$ \\
\hline MAN-JEF-01a & 5 & 47 & 2112 & 946 & 9 & 134 & 60 & 36 & 30 & 60 & 17 & 87 & 6 & 3,3 & 0,6 & 396 & 0,4 & 26 & 6,5 & 0,9 \\
MAN-JEF-02 & 14 & 93 & 952 & 424 & 14 & 167 & 170 & 42 & 50 & 30 & 60 & 17 & 86 & 8 & 4 & 0,6 & 377 & 0,4 & 13 & 1,5 & 0,2 \\
MAN-JEF-05a & 8 & 77 & 773 & 423 & 11 & 174 & 100 & 27 & 50 & 70 & 20 & 127 & 12 & 4,2 & 0,6 & 233 & 0,6 & 14 & 0,5 & 0,5 \\
MAN-JEF-05C & 12 & 95 & 390 & 496 & 17 & 162 & 100 & 22 & 60 & 40 & 100 & 20 & 113 & 11 & 3,9 & 0,5 & 136 & 0,5 & 12 & 2,4 & 0,8 \\
MAN-JEF-06 & 12 & 42 & 1.196 & 169 & 52 & 664 & & 725 & & 110 & 22 & 111 & 18 & 16,1 & 11,1 & & 0,5 & 19 & 28,8 & 0,6 \\
\hline
\end{tabular}

Tabela 2C. Composição química dos Ortogranulitos Ribeirão das Lajes. Elementos terras raras (em ppm).

\begin{tabular}{lcccccccccccccc}
\hline Amostras & La & Ce & Pr & Nd & Sm & Eu & Gd & Tb & Dy & Ho & Er & Tm & Yb & Lu \\
\hline MAN-JEF-01a & 41,6 & 72,1 & 7,45 & 27,1 & 4,3 & 1,84 & 3,1 & 0,4 & 1,8 & 0,3 & 0,9 & 0,12 & 0,8 & 0,13 \\
MAN-JEF-02 & 28,1 & 51,9 & 5,62 & 21,3 & 4 & 1,18 & 3,2 & 0,5 & 2,6 & 0,5 & 1,4 & 0,2 & 1,4 & 0,23 \\
MAN-JEF-05a & 22,2 & 39,8 & 4,32 & 16,6 & 3,3 & 1,26 & 2,8 & 0,4 & 2,3 & 0,4 & 1 & 0,13 & 0,8 & 0,13 \\
MAN-JEF-05c & 40,6 & 77,8 & 8,49 & 32,5 & 6,3 & 1,22 & 4,6 & 0,7 & 3,6 & 0,7 & 1,8 & 0,25 & 1,6 & 0,25 \\
MAN-JEF-06 & 256 & 451 & 44,8 & 152 & 23,4 & 2,13 & 16,7 & 2,3 & 11,5 & 2,1 & 5,4 & 0,72 & 4,3 & 0,66 \\
\hline
\end{tabular}




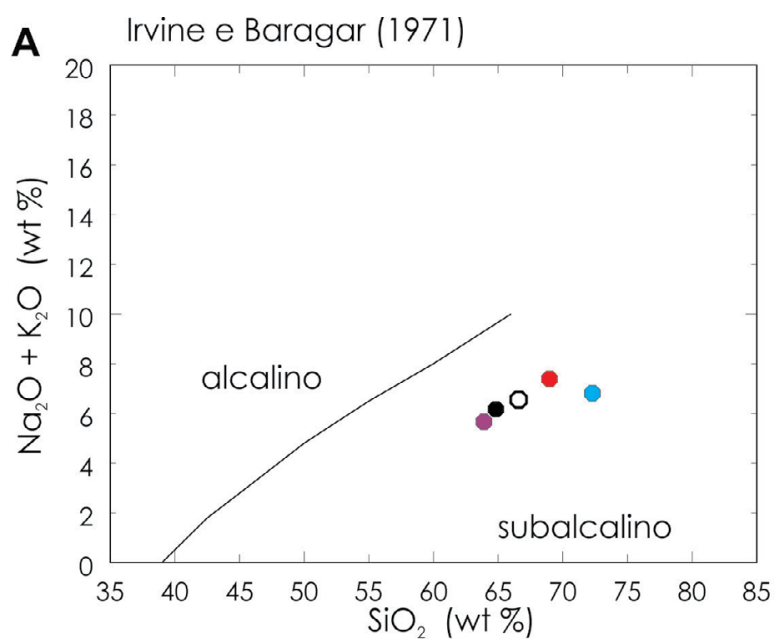

B
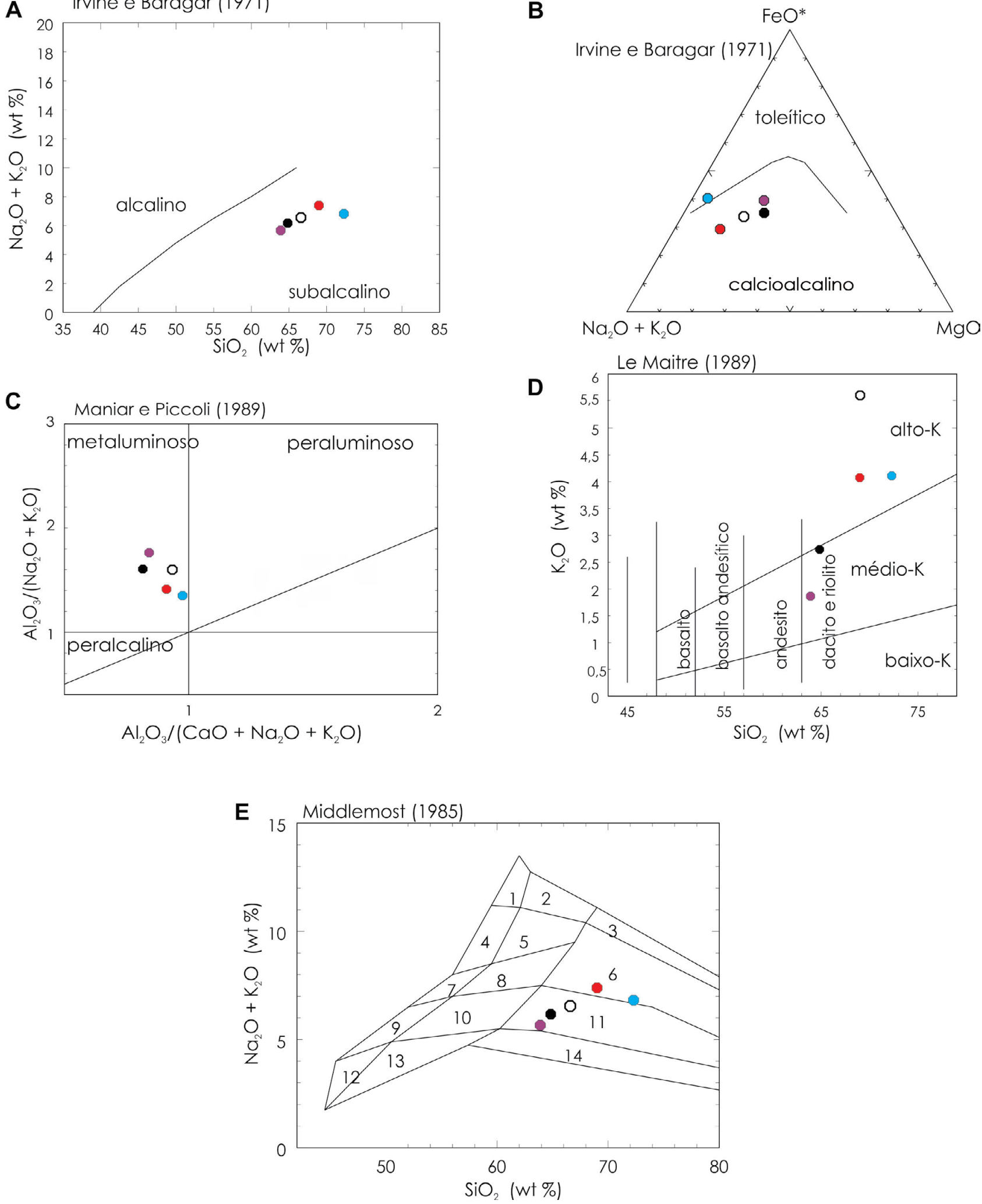

MAN-JEF-01a: círculo vermelho; MAN-JEF-02: círculo preto; MAN-JEF-05a: círculo branco; MAN-JEF-05c: círculo púrpura; MAN-JEF-06: círculo azul.

Figura 5. Diagramas discriminantes de séries magmáticas. (A) Diagrama sílica $\times$ total de álcalis de Irvine e Baragar (1971); (B) diagrama AFM de Irvine e Baragar (1971); (C) caráter metaluminoso dos ortogranulitos (Maniar e Piccoli, 1989); (D) diagrama de classificação de suítes de alto, médio e baixo-K (Le Maitre, 1989); (E) diagrama de Middlemost (1985). 

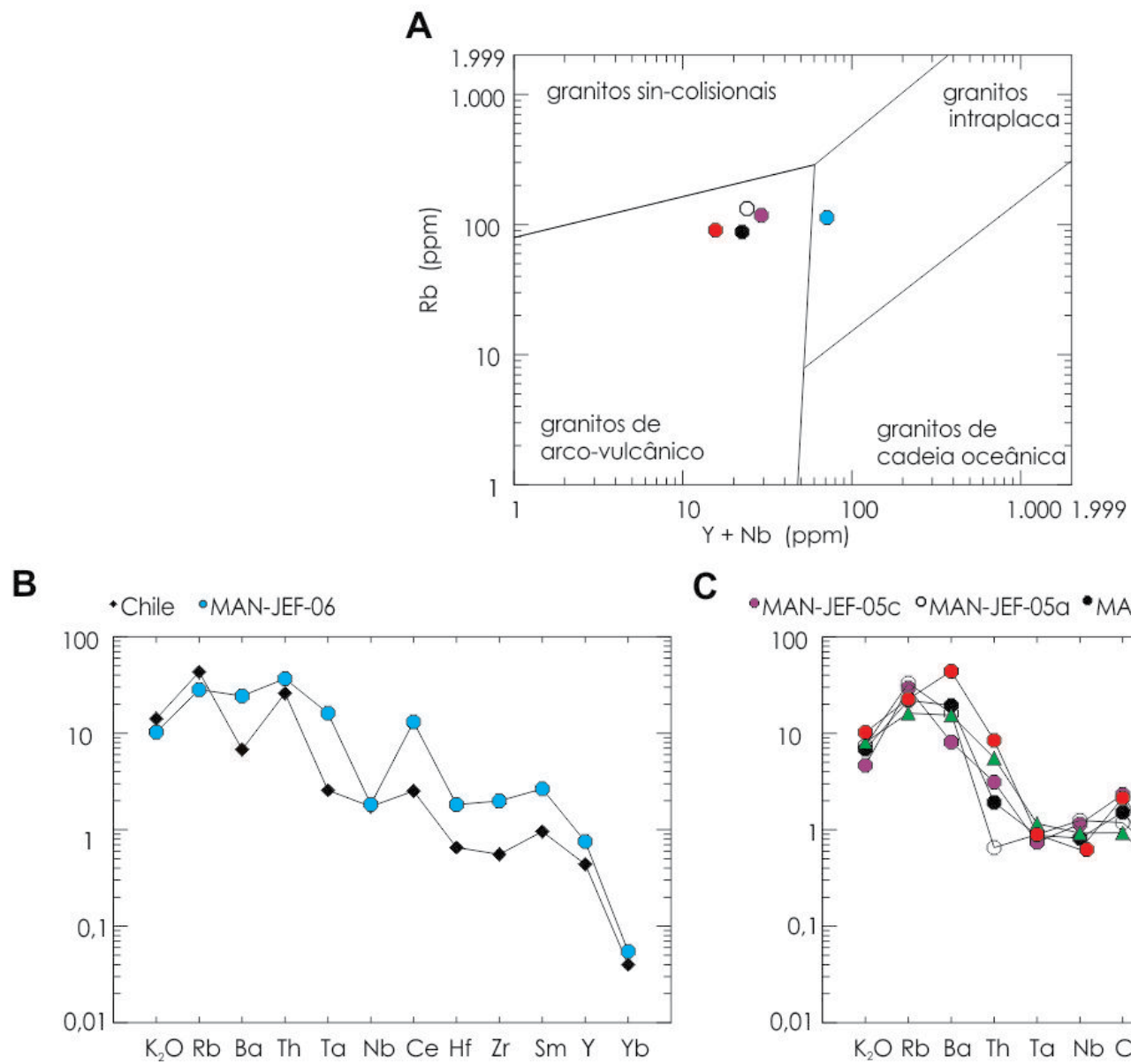

C MAN-JEF-05C OMAN-JEF-05a •MAN-JEF-02・MAN-JEF-01a $\triangle$ Jamaica

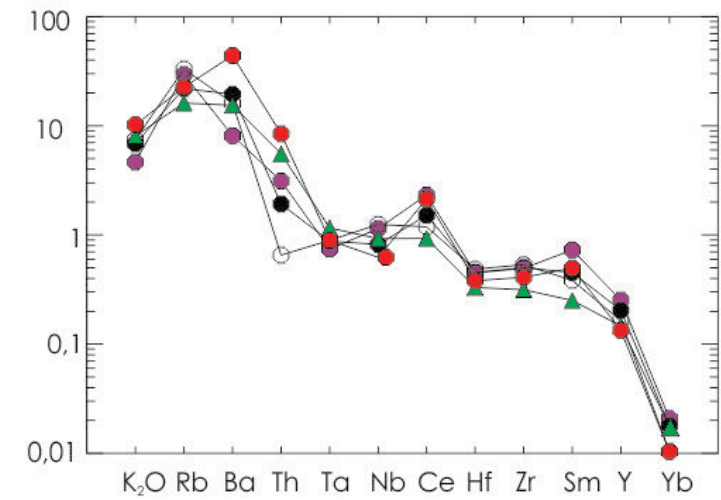

MAN-JEF-01a: círculo vermelho; MAN-JEF-02: círculo preto; MAN-JEF-05a: círculo branco; MAN-JEF-05c: círculo púrpura; MAN-JEF-06: círculo azul.

Figura 6. Diagrama de discriminação de ambiente tectônico. (A) Ortogranulitos das séries calcioalcalinas plotados no diagrama $\mathrm{Rb} \times \mathrm{Y}+\mathrm{Nb}$; (B e C) e nos aranhogramas normalizados por Ocean Ridge Granite (ORG) de Pearce et al. (1984): (B) granito de arco vulcânico do Chile (losango preto); e (C) granito de arco vulcânico da Jamaica (triângulo verde).

Tabela 3. Valores das razões $[\mathrm{La} / \mathrm{Yb}]_{N}$ dos ortogranulitos de Mangaratiba e do gnaisse leucocrático, normalizados para o condrito de Boynton (1984).

\begin{tabular}{lccc}
\hline Amostras & {$[\mathrm{La} / \mathrm{Yb}]_{\mathrm{N}}$} & $\mathrm{Eu} \mathrm{Eu}^{*}$ & $\mathrm{SiO}_{2}$ \\
\hline MAN-JEF-06 (alto-K) & 40,25 & 0,33 & 70,91 \\
MAN-JEF-01a (alto-K) & 35,16 & 1,53 & 66,35 \\
MAN-JEF-05a (alto-K) & 18,76 & 1,26 & 63,82 \\
MAN-JEF-05c (médio-K) & 17,16 & 0,69 & 61,36 \\
MAN-JEF-02 (médio-K) & 13,57 & 1,00 & 63,49 \\
\hline
\end{tabular}

de ETR, em relação às demais amostras, talvez seja pelo fato de a rocha ser mais evoluída geoquimicamente (Tabela 3). Já a amostra MAN-JEF-01a (também de alto-K e que foi analisada por $\mathrm{U} / \mathrm{Pb}$ ) (Figura 7B) possui razão [La/Yb $]_{\mathrm{N}}$ um pouco menor $(35,16)$, mas difere da amostra anterior pela menor concentração de ETR e pela pronunciada anomalia positiva de $\mathrm{Eu}^{*}(1,53)$, o que indica, provavelmente, uma fonte diferente envolvida. A outra amostra da série de alto-K (MAN-JEF-05a) (Figura 7B) possui também anomalia positiva de $\mathrm{Eu}^{*}(1,26)$, mas é menos fracionada $\left([\mathrm{La} / \mathrm{Yb}]_{\mathrm{N}}=18,76\right)$ que a amostra anterior (MANJEF-01a). Diversos autores consideram que as razões entre elementos incompatíveis não variam substancialmente em processo de cristalização fracionada, sendo esperadas variações de até 1,5 vez entre rochas cogenéticas (por exemplo, Cox et al., 1979), razão pelas quais as duas últimas amostras (Figura 7B) não fazem parte da mesma suíte.

Já as rochas da série de médio-K são as menos fracionadas $\left([\mathrm{La} / \mathrm{Yb}]_{\mathrm{N}}=13,57-17,16\right)($ Tabela 3$)$ e se diferenciam entre elas pelas anomalias de Eu*, tendo a amostra MAN-JEF-05c (Figura 7 C) uma discreta anomalia negativa $(0,69)$, enquanto a amostra MAN-JEF-02 (Figura 7C) não possui anomalia $(1,00)$. Essa diferença talvez ocorra em razão das fontes distintas ou mesmo decorrente de variações na evolução do magma. 
No geral, todas as amostras são mais enriquecidas em ETRL do que em ETRP, característica comum de rochas calcioalcalinas. Os padrões de distribuição desses elementos nos ortogranulitos podem ser observados na Figura 7.

\section{ANÁLISE ISOTÓPICA DE Nd E Sr DA AMOSTRA MAN-JEF-01a}

Para este estudo, foram realizadas análises isotópicas de rocha total no mesmo granulito (MAN-JEF-01a), datado como arqueano pelo método U-Pb em zircão $(\sim 2,65 \mathrm{Ga})$ (André et al., 2018), a fim de entender melhor a gênese desse litotipo. Assim, as razões isotópicas e o parâmetro $\varepsilon_{\mathrm{Nd}(t)}$ foram recalculados para as idades publicadas por esses autores. Os valores estão na Tabela 4.

$\mathrm{O}$ entendimento sobre o comportamento e as relações dos pares isotópicos permite a inferência sobre as fontes magmáticas envolvidas. Pois assumindo o equilíbrio isotópico entre o magma e o resíduo sólido (equilíbrio cristal-líquido) no momento da extração, as razões iniciais da amostra e da fonte serão semelhantes (Rollinson, 1993; Wilson, 1991).

\section{A MAN-JeF-06}

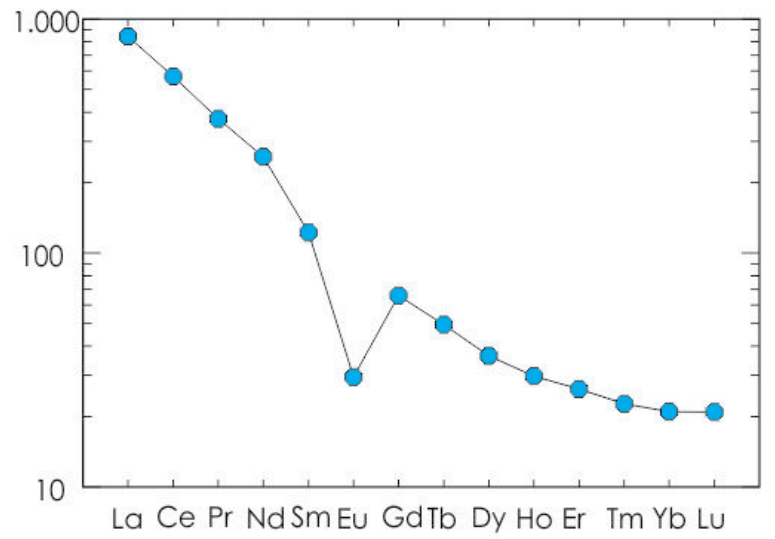

B MAN-JEF-01a MAN-JEF-05a

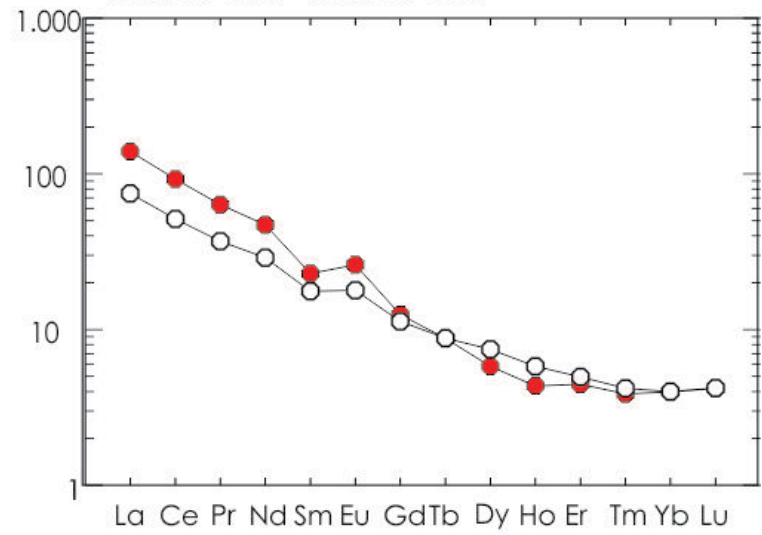

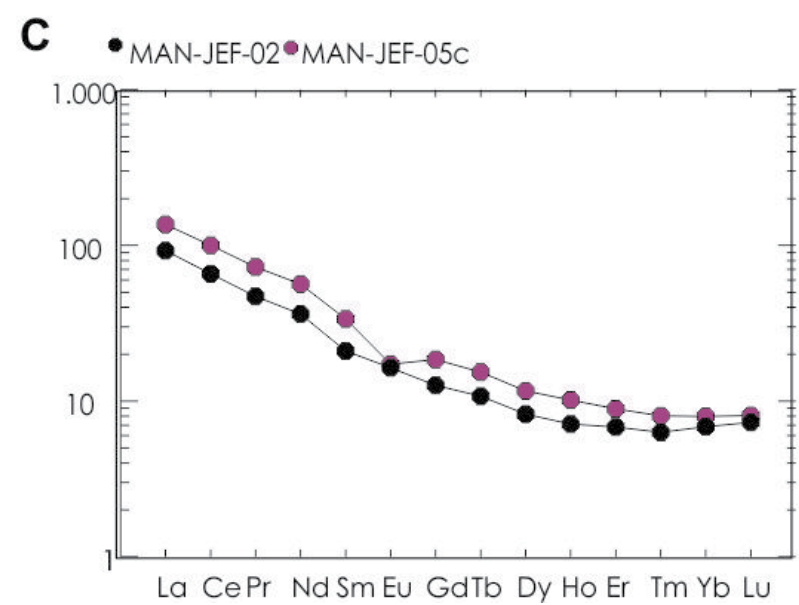

Figura 7. Padrões elementos terras raras dos ortogranulitos de Mangaratiba, Rio de Janeiro, normalizados para o condrito de Boynton (1984). (A) MAN-JEF-06 (círculo azul, alto-K); (B) MAN-JEF-01a (círculo vermelho, alto-K), MAN-JEF-05a (círculo vazio, alto-K); (C) MAN-JEF-02 (círculo preto, médio-K), MAN-JEF-05c (círculo púrpura, médio-K).

Tabela 4. Dados da análise isotópica de Rb/Sr e Sm/Nd do ortogranulito de Mangaratiba (MAN-JEF-01a).

\begin{tabular}{lcccccccc}
\hline Amostras & $\begin{array}{c}\text { Idade de } \\
\text { cristalização* }\end{array}$ & $\mathrm{T}_{\mathrm{DM}}(\mathrm{Ma})$ & $\mathrm{fSm} / \mathrm{Nd}$ & $\begin{array}{c}{ }^{143} \mathrm{Nd} / \\
{ }^{144} \mathrm{Nd}(0)\end{array}$ & $\begin{array}{c}{ }^{143} \mathrm{Nd} / \\
{ }^{144} \mathrm{Nd}(\mathrm{t})\end{array}$ & $\varepsilon_{\mathrm{Nd}(\mathrm{t})}$ & $\begin{array}{c}{ }^{87} \mathrm{Sr} /{ }^{86} \mathrm{Sr}(0) \\
{ }^{8}\end{array}$ & $\begin{array}{c}{ }^{87} \mathrm{Sr} / \\
{ }^{86} \mathrm{Sr}(\mathrm{t})\end{array}$ \\
\hline MAN-JEF-01a & $2653 \mathrm{Ma}$ & 2,7 & $-0,51$ & 0,511006 & 0,5093 & $+2,1$ & 0,714068 & 0,70529 \\
\hline
\end{tabular}

$\mathrm{T}_{\mathrm{DM}}$ : idade modelo; *idade U/Pb (André et al., 2018). 
Entretanto, é importante esclarecer que um único dado não pode ser usado para inferir a fonte desses litotipos. Por isso, não deve ser usado de forma isolada, mas em conjunto com outros dados, como de litogeoquímica e da análise U/Pb (André et al., 2018), podendo, assim, contribuir com o entendimento sobre a gênese dos Ortogranulitos Ribeirão das Lajes.

Para a amostra MAN-JEF-01a de ortogranulito calcioalcalino de composição monzogranítica, foi obtida a $\mathrm{T}_{\mathrm{DM}}$ para o manto empobrecido de $\sim 2,7 \mathrm{Ga}$. O cálculo do valor $\varepsilon_{\mathrm{Nd}(t)}$ baseado nessa idade de cristalização do protólito é $+2,1$. Quando regredidas suas razões isotópicas e comparadas no diagrama ${ }^{143} \mathrm{Nd} /{ }^{144} \mathrm{Nd} \times{ }^{87} \mathrm{Sr} /{ }^{86} \mathrm{Sr}$, o ortogranulito plota no campo I (Zindler e Hart, 1986) (Figura 8), pois sua razão ${ }^{143} \mathrm{Nd} /{ }^{144} \mathrm{Nd}_{(t)}(0,50930)$ é ligeiramente superior à do $\mathrm{CHUR}_{(\mathrm{t})}$ $(0,50920)$ e a razão ${ }^{87} \mathrm{Sr}^{86}{ }^{86} r_{(t)}(0,70529)$ é mais alta do que aquela fornecida pelo BABI $(0,7014)$, naquele momento da história da Terra (2653 Ma).

\section{DISCUSSÃO E CONCLUSÕES}

Os granulitos arqueanos $(2,65 \mathrm{Ga})$ (André et at., 2018) de Mangaratiba são homogêneos de coloração esverdeada; composicionalmente representados por granitos e granodioritos; constituídos principalmente de quartzo, K-feldspato e plagioclásio; com biotita, clinopiroxênio e ortopiroxênio como máficos mais comuns - o total dos máficos varia entre 10 e $28 \%$ para cada protólito (André et al., 2018).

A análise de litogeoquímica revela que os litotipos são metaluminosos das séries calcioalcalinas de médio a alto-K, relacionados ao arco magmático. O comportamento de ETR (Figura 7 e Tabela 3) ainda revela que devem existir diferentes suítes cogenéticas entre os granulitos estudados. A

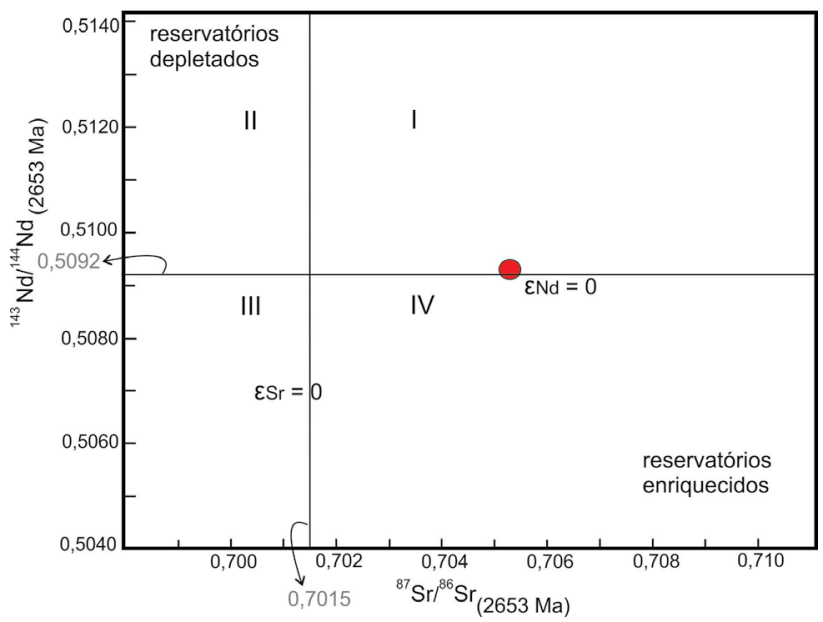

Figura 8. Diagrama de ${ }^{143} \mathrm{Nd} /{ }^{144} \mathrm{Nd}_{(t)} \times{ }^{87} \mathrm{Sr} /{ }^{86} \mathrm{Sr}_{(t)}$ de Zindler e Hart (1986). Característica da fonte mantélica do ortogranulito analisado (MAN-JEF-01a: círculo vermelho). amostra MAN-JEF-01a, por exemplo, parece ter tido a participação de uma fonte rica em feldspatos em sua gênese, o que explica a anomalia positiva de Eu*, assim como a amostra MAN-JEF-05a (ambas são da série alto-K, mas com fracionamentos diferentes) (Tabela 3). A anomalia negativa de Eu* da amostra MAN-JEF-06 (também da série alto-K) indica que houve retenção na fonte ou a participação de uma fonte empobrecida em feldspatos. O mais elevado teor de ETR dessa amostra pode indicar sua origem a partir de uma fonte mais enriquecida, embora esse enriquecimento possa ser o resultado da diferenciação magmática, pois se trata da rocha mais evoluída. Já as amostras da série médio-K possuem razões $[\mathrm{La} / \mathrm{Yb}]_{\mathrm{N}}$ próximas, o que indica fracionamento semelhante, apesar de certa diferença nas anomalias de $\mathrm{Eu}^{*}$. Isso pode também indicar fontes distintas ou variações na evolução do magma durante sua diferenciação, já que a anomalia da amostra MAN-JEF-05c é pouco acentuada e a amostra MAN-JEF-02 não possui anomalia de Eu*, o que também pode ser influenciado por variações no processo de fusão da fonte. É importante, todavia, esclarecer que este é um estudo apenas preliminar, pois com a quantidade de dados geoquímicos não é possível discutir com mais segurança os possíveis processos de diferenciação magmática envolvidos, nem fazer maiores inferências quanto à composição das fontes envolvidas. Contudo, mesmo nesse estágio em que se encontra essa investigação, é possível evidenciar que existem diferenças na evolução geoquímica das rochas.

O protólito do ortogranulito MAN-JEF-01a tem $\mathrm{T}_{\mathrm{DM}}$ de aproximadamente $2,7 \mathrm{Ga}$ e com $\varepsilon_{\mathrm{Nd}(t)}$ positivo de 2,1 , apontando para uma rocha formada a partir do manto depletado. A razão ${ }^{87} \mathrm{Sr}^{86}{ }^{86} \mathrm{Sr}_{(\mathrm{t})}(\sim 0,70529)$ é semelhante a rochas manto-derivadas de arcos continentais (Faure, 1986) e também aponta os dados de litogeoquímica. Esse ambiente geodinâmico é propício à ocorrência de assimilação de uma crosta mais antiga, o que afetaria sua razão inicial $\left({ }^{87} \mathrm{Sr}^{86}{ }^{86} \mathrm{Sr}_{(\mathrm{t})}\right)$ e explicaria a presença de cristais de zircão herdados, obtidos na análise U/Pb (LA-ICPMS) por André et al. (2018). Esse cenário geodinâmico é aceito para o Arqueano, principalmente para eventos mais recentes que $2,8 \mathrm{Ga}$ (Condie, 2005; Gerya, 2014; O'Neill e Debaille, 2014; Ernest, 2017). Temperaturas mais elevadas são sugeridas para o Arqueano, possibilitando o estabelecimento de condições de fácies granulito para o metamorfismo.

Em relação ao enquadramento regional, correlacionar esses ortogranulitos a outro terreno e inseri-los em um contexto tectônico não é uma tarefa fácil. Pelo atual conhecimento regional, observa-se semelhança entre a idade de cristalização desses ortogranulitos $(2,65 \mathrm{Ga})$ (André et al., 2018) e o intervalo do magmatismo potássico registrado no sul e no sudeste do Cráton São Francisco (2759 a 2600 Ma) (Romano et al., 2013). Nesse mesmo intervalo, são documentados, ainda, eventos metamórficos (Campos et al., 2003), sugerindo que esse foi um importante período 
de formação e retrabalhamento da crosta. O magmatismo potássico no referido cráton é interpretado como decorrente de um processo de fusão crustal (Noce et al., 1997; Noce et al., 1998; Romano et al., 2013), o qual poderia explicar os inúmeros grãos de zircão herdados no protólito desse ortogranulito monzogranítico (MAN-JEF-01a) analisado por André et al. (2018), e que também encontra semelhança no fato de pertencer à série calcioalcalina alto-K. No entanto, as rochas estudadas por esses autores (Noce et al., 1997; Noce et al., 1998; Romano et al., 2013; Moreno et al., 2017) são granitoides peraluminosos, em geral $\operatorname{com} \varepsilon_{\mathrm{Nd}(t)}$ negativos, indicando fusão de crosta. Por outro lado, os granulitos aqui estudados são metaluminosos, das séries médio a alto-K, e o ortogranulito (MAN-JEF-01a) analisado por André et al. (2018), com muitos cristais de zircão herdados, possui $\varepsilon_{\mathrm{Nd}(t)}$ positivo $(+2,1)$, apontando para a participação de uma fonte mantélica.

Suítes de granodiorito-granitos são expressivas em diversos outros terrenos arqueanos (Condie, 1994), como no Cráton do Congo (Shang et al., 2007) e no Amazônico (Silva e Oliveira, 2013), porém associadas normalmente com terrenos tonalito-trondhjemito-granodiorito (TTGs), o que não acontece com os Ortogranulitos Ribeirão das Lajes (André et al., 2018), pois não ocorrem terrenos TTGs na região, pelo menos no atual estado do conhecimento geológico. Isso mostra a necessidade de mais estudos na região sul do Orógeno Ribeira, para contextualizar esses granulitos regionalmente.

A história do Arqueano no estado do Rio de Janeiro é ainda pouco conhecida, sendo, portanto, necessários estudos adicionais para melhor entender a evolução geológica dessas rochas e o seu significado tectônico, inclusive para delimitar seus corpos. Por fim, com base nos dados apresentados neste trabalho e por André et al. (2018), sugere-se que os Ortogranulitos Ribeirão das Lajes, da região de Mangaratiba, foram formados em um ambiente de arco magmático no Neoarqueano (ca. 2,65 Ga) (André et al., 2018), com a participação de uma fonte mantélica e assimilação de rochas crustais.

\section{AGRADECIMENTOS}

Os autores agradecem à Coordenação de Aperfeiçoamento de Pessoal de Nível Superior (CAPES) a bolsa de Doutorado fornecida ao primeiro autor durante o desenvolvimento de seu projeto no Programa de Pós-Graduação em Análise de Bacias e Faixas Móveis da Faculdade de Geologia da Universidade do Estado do Rio de Janeiro (FEGL/UERJ). Aos Doutores Mauro Geraldes, Rodrigo Peternel, Sérgio Valente e Ciro Ávila as discussões dos dados. À Ivone Keiko e à Profa. Dra. Marly Babinski, da Universidade de São Paulo (USP), a ajuda na regressão dos dados isotópicos.

\section{REFERÊNCIAS}

André, J. L. F., Valladares, C. S., Duarte, B. P. (2018). Granulitos Arqueanos na Região de Mangaratiba (RJ): Significado Tectônico. Anuário do Instituto de Geociências - UFRJ, 41(3), 531-547. https://doi.org/10.11137/2018_3_531_547

Boynton, W. R. (1984). Cosmochemistry of the rare earth elements meteorite studies. In: P. Henderson (Ed.), Rare Earth Element Geochemistry (v. 2, p. 63-114). Amsterdã: Elsevier. https://doi.org/10.1016/B978-0-444-42148-7.50008-3

Campos, J. C. S., Carneiro, M. A., Basei, M. A. S. (2003). $\mathrm{U}-\mathrm{Pb}$ evidence for late Neoarchean crustal reworking in the Southern São Francisco Craton (Minas Gerais, Brazil). Anais da Academia Brasileira de Ciências, 75(4), 497-511. https://doi.org/10.1590/S0001-37652003000400008

Condie, K. C. (1994). Archean crustal evolution. Amsterdã: Elsevier. v. 11, 528 p.

Condie, K. C. (2005). Earth as an Evolving Planetary system. Burlington: Elsevier. https://doi.org/10.1016/C2015-0-00179-4

Cordani, U. G., Delhal, J., Ledent, D. (1973). O. Orogenéses superposeés dans le Précambrien du Brésil sud-oriental (États du Rio de Janeiro et de Minas Gerais). Revista Brasileira de Geociências, 3(1), 1-22.

Cox, K. G., Bell, J. D., Pankhurst, R. T. (1979). The interpretation of the igneous rocks. Chicago: University Chicago Press. https://doi.org/10.1007/978-94-017-3373-1

Delhal, J., Ledent, D., Cordani, U. G. (1969). Ages Pb/U, Sr/ $\mathrm{Rb}$ et $\mathrm{Ar} / \mathrm{K}$ de formations métamorphiques et granitique du Sud-Est du Brésil (États de Rio de Janeiro et de Minas Gerais). Annales de la Societé Geologiqué Belgique, 92, 271-283.

DePaolo, D. J. (1981). Trace element and isotopic effects of combined wallrock assimilation and fractional crystallization. Earth and Planetary Science Letters, 53(2), 189-202. https:// doi.org/10.1016/0012-821X(81)90153-9

Dios, F. R. B. (1995). Geologia, petrologia e metamorfismo dos terrenos de alto grau da porção norte da Folha Mangaratiba (1:50.000). Dissertação (Mestrado). Rio de Janeiro: Instituto de Geociências - UFRJ.

Duarte, B. P. (1998). Evolução tectônica dos ortognaisses do Complexo Juiz de Fora e Mantiqueira na região de Juiz de Fora (MG): geologia, petrologia e geoquímica. Tese (Doutorado). São Paulo: Instituto de Geociências - USP. https://doi.org/10.11606/T.44.2016.tde-05012016-153129 
Duarte, B. P., Heilbron, M., Campos Neto, M. C. (2000). Granulite/Charnockite from the Juiz de Fora Domain, Central Segment of the Brasiliano - Pan-African Ribeira Belt. Revista Brasileira de Geociências, 30(3), 358-362. https://doi.org/10.25249/0375-7536.2000303358362

Ernest, W. G. (2017). Earth's thermal Evolution, mantle convection, and Hadean onset of plate tectonics. Journal of Asian Earth Science, 145(Parte B), 334-348. https://doi. org/10.1016/j.jseaes.2017.05.037

Faure, G. (1986). Principles of isotope geology. Nova York: John Wiley \& Sons. https://doi.org/10.1017/ S0016756800017453

Fernandes André, J. L. (2014). Comparação entre o Complexo Juiz de Fora e a Unidade Granulitica Ponte de Zinco: geocronologia U-Pb em zircão (LA-ICPMS), geoquímica isotópica e composição das fontes geradoras. Tese (Doutorado). Rio de Janeiro. Faculdade de Geologia - UERJ.

Fernandes André, J. L, Valladares, C. S., Duarte, B. P. (2009). O Complexo Juiz de Fora na região de Três Rios (RJ): litogeoquímica, geocronologia U-Pb (LA-ICPMS) e geoquímica isotópica de Nd- e Sr. Revista Brasileira de Geociências, 39(4), 773-793. https://doi. org/10.25249/0375-7536.2009394773793

Gerya, T. V. (2014). Precambrian geodynamics: Concepts and models. Gondwana Research, 25(2), 442-463. https:// doi.org/10.1016/j.gr.2012.11.008

Heilbron, M. (1993). Evolução tectono-metamórfica da seção Bom Jardim de Minas-MG - Barra do Pirai-RJ, setor central da Faixa Ribeira. Tese (Doutorado). São Paulo: Instituto de Geociências - USP. https://doi.org/10.11606/T.44.1993. tde-23062015-152138

Heilbron, M., Almeida, J. C. H., Silva, L. G. E., Palermo, N., Tupinambá, M., Duarte, B. P., Valladares, C. S., Ramos, R. C., Sanson, M., Guedes, E., Gontijo, A., Nogueira, J. R., Valeriano, C., Ribeiro, A., Ragatky, C. D., Miranda, A., Sanches, L., Melo, C. L., Roig, H. L., Dios, F. B., Fernández, G., Neves, A., Guimarães, P., Dourado, F., Lacerda, V. G. (2007a). Angra dos Reis- SF.23-Z-C-II, escala 1:100.000: nota explicativa integrada com as folhas Santa Rita do Jacutinga, Barra do Piraí, Volta Redonda e Angra dos Reis, escala 1:100.000. Rio de Janeiro/São Paulo: Companhia de Pesquisa de Recursos Minerais - CPRM. Disponível em: $<$ http://rigeo.cprm.gov.br/ jspui/handle/doc/10310>. Acesso em: 22 dez. 2020.

Heilbron, M., Almeida, J. C. H., Silva, L. G. E., Palermo, N., Tupinambá, M., Duarte, B. P., Valladares, C. S., Ramos, R. C.,
Sanson, M., Guedes, E., Gontijo, A., Nogueira, J. R., Valeriano, C., Ribeiro, A., Ragatky, C. D., Miranda, A., Sanches, L., Melo, C. L., Roig, H. L., Dios, F. B., Fernández, G., Neves, A., Guimarães, P., Dourado, F., Lacerda, V. G. (2007b). Volta Redonda-SF.23-Z-A-V, escala 1:100.000: nota explicativa integrada com as folhas Santa Rita do Jacutinga, Barra do Piraí, Volta Redonda e Angra dos Reis, escala 1:100.000. Rio de Janeiro/São Paulo: Companhia de Pesquisa de Recursos Minerais - CPRM. Disponível em: <http://rigeo.cprm.gov.br/ jspui/handle/doc/10306>. Acesso em: 22 dez. 2020.

Heilbron, M., Duarte, B. P., Valeriano, C. M, Simonetti, A., Machado, N., Nogueira, J. R. (2010). Evolution of reworked Paleoproterozoic basement rocks within the Ribeira belt (Neoproterozoic), SE-Brazil, based on U Pb geochronology: Implications for paleogeographic reconstructions of the São Francisco-Congo paleocontinent. Precambrian Research, 178(1-4), 136-148. https://doi.org/10.1016/j. precamres.2010.02.002

Heilbron, M., Machado, N. (2003). Timing of terrane accretion in the Neoproterozoic Eopaleozoic Ribeira orogen (SE Brazil). Precambrian Research, 125(1-2), 87-112. https:// doi.org/10.1016/S0301-9268(03)00082-2

Heilbron, M., Pedrosa-Soares, A. C., Campos Neto, M. C., Silva, L. C., Trouw, R. A. J., Janasi, V. A. (2004). Província Mantiqueira. In: V. Mantesso-Neto, A. Bartorelli, C. D. R. Carneiro, B. B. Brito Neves (Eds.), Geologia do Continente Sul-Americano: Evolução da Obra de Fernando Flávio Marques de Almeida (p. 203-234). São Paulo: Beca. Disponível em: $<\mathrm{http} / / /$ sbg.sitepessoal.com/livrosadobados/ geologiaSul.pdf >. Acesso em: 22 dez. 2020.

Heilbron, M., Silva, L. G. E., Almeida, J. C. H. (2016). Geologia e recursos minerais do Estado do Rio de Janeiro: texto explicativo do mapa geológico e de recursos minerais. Belo Horizonte: Companhia de Pesquisa de Recursos Minerais - CPRM. Disponível em: <http://rigeo.cprm.gov.br/jspui/ handle/doc/18458>. Acesso em: 22 dez. 2020.

Irvine, T. N., Baragar, W. R. A. A. (1971). Guide to the chemical classification of the common volcanic rocks. Canadian Journal of Earth Science, 8(5), 523-548. https:// doi.org/10.1139/e71-055

Le Maitre, R. W. (1989). A Classification of Igneous Rocks and Glossary of Terms. Oxford: Blackwell Science.

Machado, N., Schrank, A., Noce, C. M., Gauthier, G. (1996). Ages of detrital zircon from ArcheanPaleoproterozoic sequences: implications for Greenstone Belt setting and evolution of a Transamazonian foreland 
basin in Quadrilátero Ferrífero, southeast Brazil. Earth Planetary Science Letters, 141(1-4), 259-276. https://doi. org/10.1016/0012-821X(96)00054-4

Maniar, P. D., Piccoli, P. M. (1989). Tectonic discrimination of granitoids. Geological Society of American Bulletin, 101(5), 635643. https://doi.org/10.1130/0016-7606(1989)101<0635:TDO $\mathrm{G}>2.3 . \mathrm{CO} ; 2$

Middlemost, E. A. K. (1985). Magmas and magmatic rocks. Londres: Longman Press.

Moreno, J. A., Baldim, M. R., Semprich, J., Oliveira, E. P., Verma, S. K., Teixeira, W. (2017). Geochronological and geochemical evidence for extension-related Neoarchean granitoids in the southern São Francisco Craton, Brazil. Precambrian Research, 294, 322-343. https://doi. org/10.1016/j.precamres.2017.04.011

Noce, C. M., Machado, N., Teixeira, W. (1998). U-Pb geochronology of gneisses and granitoids in the Quadrilátero Ferrífero (southern São Francisco craton): age constraints for Archean and Paleoproterozoic magmatism and metamorphism. Revista Brasileira de Geociências, 28, 95-102. https://doi. org/10.25249/0375-7536.199895102

Noce, C. M., Pedrosa-Soares, A. C., Silva, L. C., Armstrong, R., Piuzana, D. (2007). Evolution of polycyclic basement complexes in the Araçuaí Orogen, based on U-Pb SHRIMP data: Implications for Brazil-Africa links in Paleoproterozoic time. Precambrian Research, 159(1-2), 60-78. https://doi. org/10.1016/j.precamres.2007.06.001

Noce, C. M., Teixeira, W., Machado, N. (1997). Geoquímica dos gnaisses TTG e granitóides neoarqueanos do Complexo Belo Horizonte, Quadrilátero Ferrífero, Minas Gerais. Revista Brasileira de Geociencias, 27(1), 25-32. https:// doi.org/10.25249/0375-7536.19972532

Nogueira, J. R., Choudhuri, A., Bello, R. M. (2004). Inclusões fluidas e caminhos P-T retrometamórficos em granulitos do Complexo Juiz de Fora. Revista Brasileira de Geociências, 34(4), 509-520. https://doi. org/10.25249/0375-7536.2004344509520

O'Neill, C., Debaille, V. (2014). The Evolution of HadeanEoarchean geodynamics. Earth and Planetary Science Letters, 406, 49-58. https://doi.org/10.1016/j.epsl.2014.08.034

Pearce, J. A., Harris, N. B. W., Tindle, A. G. (1984). Trace element discrimination diagrams for the tectonic interpretation of granitic rocks. Journal of Petrology, 25(4), 956-983. https://doi.org/10.1093/petrology/25.4.956
Rollinson, H. (1993). Using geochemical data: evaluation, presentation, interpretation. Boca Raton, USA: Routledge Taylor \& Francis Group. https://doi. org/10.4324/9781315845548

Romano, R., Lana, C., Alkmim, F. F., Stevens, G. S., Armstrong, R. (2013). Stabilization of the southern portion of the São Francisco Craton, SE Brazil, through a long-lived period of potassic magmatism. Precambrian Research, 224, 143-159. https://doi.org/10.1016/j. precamres.2012.09.002

Sato, K., Tassinari, C. C. G., Kawashita, K., Petronilho, L. (1995). O método geocronológico Sm-Nd no IG/ USP e suas aplicações. Anais da Academia Brasileira de Ciências, 67, 312-335. Disponível em: <http:// memoria.bn.br/DocReader/158119/33495>. Acesso em: 16 dez. 2020.

Shang, C. K., Satir, M., Nsifa, E. N., Liégeois, J. P., Siebel, W., Taubald, H. (2007). Archaean high-K granitoids produced by remelting of the earlier Tonalite - Trondhjemite - Granodiorite (TTG) in the Sangmelima region of the Ntem complex of the Congo craton, southern Cameroon. International Journal of Earth Science, 96(5), 817-841. https://doi.org/10.1007/ s00531-006-0141-3

Silva, C. R. P., Oliveira, D. C. (2013). Geologia, petrografia e geoquímica das associações TTG e leucogranodioritos do extremo norte do Domínio Rio Maria, província de Carajás. Boletim do Museu Paraense Emilio Goeldi Ciências Naturais, 8(3), 383-415. Disponível em: <http://editora.museu-goeldi. br/bn/artigos/cnv8n3_2013/geologia(ronaib).pdf $>$. Acesso em: 16 dez. 2020.

Sperling, E. V., Baltazar, O. F., Vieira, V. S. (1983). Projeto Carta Geológica do Estado do Rio de Janeiro. Folhas Mangaratiba, Ilha Grande, Angra dos Reis, Rio Mambucaba, Cunha, Picinguaba Juatinga e Cunhambebe. Relatório Final. Niterói: CPRM/DRM. Disponível em: <http://rigeo.cprm. gov.br/jspui/handle/doc/6970>. Acesso em: 18 dez. 2020.

Streckeisen, A. L. (1976). To each plutonic rock its proper name. Earth Science Reviews, 12(1), 1-33. https://doi. org/10.1016/0012-8252(76)90052-0

Wilson, M. (1991). Igneous Petrogenesis: a global tectonic approach. Londres: Unwin Hyman. https://doi. org/10.1007/978-1-4020-6788-4

Zindler, A., Hart, S. (1986). Chemical geodynamics. Annual Reviews Earth Planetary Science, 14, 493-571. https://doi. org/10.1146/annurev.ea.14.050186.002425 